\title{
Diabetes mellitus type 2 reduces the viability, proliferation, and angiogenic marker of adipose-derived stem cells cultured in low-glucose anti-oxidant-serum supplemented medium
}

\author{
Karina ${ }^{1,2,3},{ }^{*}$, lis Rosliana ${ }^{2}$, Siti Sobariah ${ }^{2}$, Imam Rosadi ${ }^{2,4}$, Irsyah Afini ${ }^{2}$, Tias Widyastuti' ${ }^{2}$, Melinda Remelia ${ }^{1}$, \\ Dewi Sukmawati ${ }^{5}$, Jeanne Adiwinata Pawitan ${ }^{5,6,7}$
}

\begin{abstract}
${ }^{I}$ Doctoral Program of Biomedical Sciences, Faculty of Medicine, Universitas Indonesia, Jakarta, Indonesia
\end{abstract}

${ }^{2}$ HayandraLab, Yayasan Hayandra Peduli, Jakarta, Indonesia

${ }^{3}$ Klinik Hayandra, Yayasan Hayandra Peduli, Jakarta, Indonesia

${ }^{4}$ Master Degree of Biotechnology, Institut Teknologi Bandung, Bandung, Indonesia

${ }^{5}$ Department of Histology, Faculty of Medicine, Universitas Indonesia,

Jakarta, Indonesia

Correspondence

Karina, Doctoral Program of Biomedical Sciences, Faculty of Medicine,

Universitas Indonesia, Jakarta, Indonesia

HayandraLab, Yayasan Hayandra Peduli, Jakarta, Indonesia

Klinik Hayandra, Yayasan Hayandra Peduli, Jakarta, Indonesia

Email: karina@hayandra.com

History

- Received: Jan 15, 2019

- Accepted: Mar 17, 2019

- Published: Mar 31, 2019

DOI :

https://doi.org/10.15419/bmrat.v6i3.530

\section{Check for updates}

\section{Copyright}

(c) Biomedpress. This is an openaccess article distributed under the terms of the Creative Commons Attribution 4.0 International license.

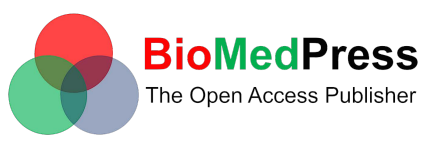

\begin{abstract}
Introduction: Hyperglycemia in diabetic patients induces elevated pro-inflammatory cytokine production, resulting in cellular damage, which may affect the regenerative function of mesenchymal stem cells (MSCs), such as adipose-derived stem cells (ADSCs). Identifying the effect of diabetes on ADSCs and optimization of culture conditions is therefore an important starting point for the application of autologous stem cells to improve clinicial outcomes. The aim of this study was to investigate the effect of diabetes on ADSCs that cultured in low-glucose anti-oxidant-serum supplemented medium. Methods: In this study, freshly isolated stromal vascular fraction (SVF) and expanded ADSCs were compared between diabetic and non-diabetic donors. SVF were isolated from the abdominal fat, and total viable cells and viability were estimated. Fresh SVF were cultured in low-glucose $(100 \mathrm{mg} / \mathrm{dL})$ culture medium supplemented with an anti-oxidant and fetal bovine serum (complete culture medium) at a low density for 14 days for the colony formation unit-fibroblast (CFU-F) assay. The remaining SVF were expanded to obtain ADSCs in the complete culture medium, which were evaluated based on MSCs surface marker expression and three lineage differentiation potential. Diabetic and non-diabetic ADSCs were compared with respect to population doubling time and viability after serial passage. Results: Total viable counts $(0.97 \pm$ $0.39 \times 10^{9}$ cells $/ 10 \mathrm{~mL}$ of adipose tissue, $0.56 \pm 0.39 \times 10^{9}$ cells $/ 10 \mathrm{~mL}$ of adipose tissue, $\mathrm{p}=0.02$, independent $t$-test), but not viability ( $98.63 \pm 1.12 \%, 98.20 \pm 1.21 \%, p=0.38$, independent $t$-test), were significantly higher for SVF cells from adipose tissues of non-diabetic donors than diabetic donors. Fewer CFU-F were obtained from cultured diabetic SVF than from non-diabetic SVF. Diabetic and non-diabetic ADSCs had similar differentiation potency and CD73 $(99.44 \pm 0.34 \%, 97.15$ $\pm 5.37 \%, p=0.21$, Mann-Whitney U test) and CD90 (97.30 $\pm 2.86 \%, 95.06 \pm 6.32 \%, p=0.90$, MannWhitney U test) expression, but significantly fewer diabetic ADSCs expressed CD105 or endoglin, a marker for angiogenesis (89.91 $\pm 7.14 \%, 57.90 \pm 21.36 \%$ for non-diabetic and diabetic groups, $\mathrm{p}<$ 0.001 , Mann-Whitney U test). Diabetic ADSCs tended to exhibit slower proliferation (4.43 \pm 2.70 days, $3.04 \pm 0.55$ days, $p=0.27$ in passage 2 (P2); $3.95 \pm 1.55$ days, $2.96 \pm 0.91$ days, $p=0.21$ in $P 3$, independent $t$-test) and lower viability than those of non-diabetic ADSCs (77.65 $\pm 10.61 \%, 87.13 \pm$ $10.06 \%, p=0.25$ in P2; $82.70 \pm 8.07 \%, 91.15 \pm 3.77 \%, p=0.04$ in P3, independent $t$-test). Culture in low-glucose anti-oxidant-serum supplemented medium did not improve CD105 expression (65.14 $\pm 5.86 \%, 71.06 \pm 10.27 \%, 64.05 \pm 10.04 \%, p=0.70$, for P1, P2, and P3, respectively, repeated measure ANOVA) and cell proliferation ( $p=0.50$ for P2 vs. P3, paired $t$-test) of diabetic ADSCs. Conclusions: Overall, diabetes reduced CD105 expression and ADSCs proliferation, suggesting that the angiogenic potency of diabetic ADSCs is reduced. The diabetic ADSCs in this study were also more prone to cell death caused by handling technique compared to non-diabetic ADSCs. Therefore, more advanced culture techniques should be applied to expand ADSCs from diabetic patients to achieve expected clinical outcomes.
\end{abstract}

Key words: adipose-derived stem cells, CFU-F, cell viability, diabetic, endoglin

\section{INTRODUCTION}

Diabetes mellitus (DM) is metabolic disorder characterized by a high blood glucose concentration (hyperglycemia) caused by insulin resistance, defects in insulin secretion, or a combination of both. Hyperglycemia up-regulates reactive oxygen species (ROS) production, suppresses the nitric oxide (NO) synthesis pathway, and decreases the bioavailability of NO, thereby inducing endothelial dysfunction ${ }^{1,2}$. Longterm uncontrolled hyperglycemia leads to the development of micro- and macrovascular complications, resulting in damage and organ failure, such as the eyes, kidneys, nerves, and hearts ${ }^{3}$. Although phar-
Cite this article : Karina, Rosliana I, Sobariah S, Rosadi I, Afini I, Widyastuti T, Remelia M, Sukmawati D, Adiwinata Pawitan J. Diabetes mellitus type 2 reduces the viability, proliferation, and angiogenic marker of adipose-derived stem cells cultured in low-glucose anti-oxidant-serum supplemented medium. Biomed. Res. Ther.; 6(3):3073-3082. 
${ }^{6}$ Stem Cell Medical Technology Integrated Service Unit, Cipto Mangunkusumo Central HospitalFaculty of Medicine, Universitas Indonesia, Jakarta, Indonesia

${ }^{7}$ Stem Cell and Tissue Engineering Research Center, Indonesia Medical Education and Research Institute (IMERI), Faculty of Medicine, Universitas Indonesia, Jakarta, Indonesia macotherapy can control glucose levels, most cases of diabetes are diagnosed after vascular complications have developed, and the damage cannot be reversed $^{4,5}$.

The potency of mesenchymal stem cells (MSCs) for DM has been studied extensively using cells, animals, and humans ${ }^{6-11}$. MSCs have self-renewal, homing, and regenerative capacity, immunomodulation, antiinflammation, as well as protective effects against apoptosis and oxidative stress by a paracrine mechanism; accordingly, they are beneficial for cellular and tissue regeneration in $\mathrm{DM}^{5,12}$. However, some studies have revealed that diabetes may impair the regenerative function of MSCs from bone marrow and adipose tissues ${ }^{7,13}$. The diabetic MSCs have a reduction in their proliferation, survival, homing, and angiogenic capacity, compared to their non-diabetic counterparts $^{7,13}$. Bone marrow is the primary source of MSCs for regenerative therapy. However, adiposederived stem cells (ADSCs) are easier to obtain by a lower risk procedure compared to bone marrowderived MSCs (BMSCs). Since the use of high glucose $(500 \mathrm{mg} / \mathrm{dL}$ and $1000 \mathrm{mg} / \mathrm{dL})$ medium result in a reduce of stem cell proliferation, ${ }^{14}$ in vitro studies have typically used MSCs cultured in low glycemic conditions, which could reverse some of the damaged diabetic MSCs function ${ }^{7,13}$. To improve MSCs proliferation and slow the aging process, several anti-oxidants have been added to culture medium ${ }^{15,16}$. In this study, we compared the biological properties of diabetic and non-diabetic ADSCs in low-glycemic culture conditions $(100 \mathrm{mg} / \mathrm{dL})$ with anti-oxidant supplementation.

\section{METHODS}

All procedures to obtain adipose tissue samples from donors have been approved by the Health Research Ethics Commitee of the University of Indonesia and Cipto Mangunkusumo Hospital (\#628/UN2.F1/ETIK/2016 and \#485/UN2.F1/ETIK/2017). Informed consent was obtained before all research procedures.

\section{Patients}

Abdominal subcutaneous fat was aspirated from 10 non-diabetic donors and 15 donors with diabetes type 2 (aged 40-72 years) by liposuction. All patients were recruited at Klinik Hayandra, Jakarta, between August 1, 2016, and July 28, 2017. Diabetic donors were selected to those who had diabetes duration of less than 5 years and were taking oral anti-diabetic medication to control blood glucose levels. Patients with cancer, autoimmune, and acute or chronic inflammatory diseases were excluded from both groups.

\section{Stromal Vascular Fraction Preparation}

Aspirated abdominal subcutaneous fat samples, called lipoaspirates, were processed to isolate stromal vascular fractions (SVF) using a previously described patented method, with modifications ${ }^{17}$. In brief, H-Remedy enzyme solution was used to digest lipoaspirates for 1 hour at $37^{\circ} \mathrm{C}$. After incubation, low-glucose (100 mg/dL) Dulbecco's Modified Eagle's Medium (DMEM) containing $4 \mathrm{mM}$ L-glutamine was used to inactivate the enzyme. Digested lipoaspirates were centrifuged for 5 minutes at $600 \times g$. The supernatant was discarded and the cell pellets were lysed using red cell buffer lysis for 10 minutes at room temperature $\left(20-25^{\circ} \mathrm{C}\right)$. After centrifugation, the pellets were washed using phosphate-buffered saline (PBS) at pH 7.4 and centrifuged to obtain SVF. The SVF were diluted in saline solution. Viable and dead cells were counted to calculate cell viability using the formula below.

cell viability $(\%)=\frac{\text { number of viable cells }}{\text { number of dead and viable cells }}$

Numbers of viable stromal cells were calculated per 10 $\mathrm{mL}$ of adipose tissue digested.

\section{Adipose-Derived Mesenchymal Stem Cells Culture}

Freshly isolated stromal cells were cultured in 25 $\mathrm{cm}^{2}$ flasks with vented filter caps at a density of $125 \times 10^{3}$ cells per flask. Complete culture medium composed of DMEM containing $100 \mathrm{mg} / \mathrm{dL}$ glucose, 4 mM L-glutamine (Gibco, Gaithersburg, MD, USA) supplemented with $10 \%$ fetal bovine serum (FBS) (Gibco), 1\% antibiotic-antimycotic solution (10,000 units $/ \mathrm{mL}$ penicillin, $10,000 \mu \mathrm{g} / \mathrm{mL}$ streptomycin, and $25 \mu \mathrm{g} / \mathrm{mL}$ amphotericin B) (Gibco), and $0.05 \mathrm{ng} / \mathrm{mL}$ L-ascorbic acid (LAA) was used ${ }^{16}$. After two days, some of fibroblast-like cells adhered to the flask, then half of the culture medium was removed. After another two days, culture medium along with nonadherent cells were removed, and medium was replaced with fresh one. Medium was changed again every 2-3 days. Adherent cells were sub-cultured after reaching $70-80 \%$ confluency.

\section{Colony Forming Unit-Fibroblast Assay}

Colony forming unit-fibroblast (CFU-F) assays were performed to analyze the clonogenic potential of MSCs population in SVF from diabetic and nondiabetic donors. Freshly isolated SVF were seeded in $9 \mathrm{~cm}^{2}$ dish at seeding densities of $10 \times 10^{3}, 15 \times 10^{3}$, and $20 \times 10^{3}$ cells per dish and cultured in complete culture medium described previously ${ }^{18}$. Variety of 
cell seeding number was implemented since the lowest and highest CFU-F numbers were expected to be obtained from diabetic and non-diabetic groups. After 14 days, plastic-adherent cells were rinsed twice with PBS, fixed with methanol for 5 minutes, air dried, stained with filtered $0.4 \%$ Giemsa solution (SigmaAldrich, Spruce Street, St. Louis, MO) for 10 minutes, and rinsed with PBS. Cells were observed under an inverted microscope at $4 \times$ magnification. Aggregates with more than 50 cells were counted as one colony. All assays were performed in duplicate.

\section{Cell Differentiation Assay}

ADSCs at passage 3 were seeded in 24-well plates at $2 \times 10^{5}$ cells per well. After cells reached $70-80 \%$ confluency, they were cultured under osteogenic, chondrogenic, and adipogenic conditions using the STEMPRO Osteogenesis, Chondrogenesis, and Adipogenesis Differentiation medium (Thermo Fisher Scientific, Waltham, MA), as described by the manufacturer. Cell differentiation was observed after 4 days of induction. Oil red $\mathrm{O}$, alizarin red, and alcian blue staining were used to identify adipocytes, osteocytes, and chondrocytes, respectively, following methods described elsewhere ${ }^{19}$.

\section{ADSC Surface Markers Expression Analysis by Flow Cytometry}

Passage 1 ADSCs from 8 diabetic donors and 4 nondiabetic donors were used for MSCs phenotyping using a 3 laser and 10 channel multiparameter flow cytometer (Miltenyi Biotec, Bergisch Gladbach, Germany). Cells $\left(2.10^{5}\right.$ cells per tube) were stained with antibodies against CD73-APC, CD90-FITC, and CD105-PerCP Cy5.5 as positive MSCs markers $(2 \mu \mathrm{L}$ cocktail), and lineage-negative-PE cocktail $(2 \mu \mathrm{L})$, a mixture of CD34, CD45, CD11b, CD19, and HLA-DR (BD Stemflow hMSC Analysis Kit, BD Biosciences, Franklin Lakes, NJ, USA) as positive hematopoetic cells markers. Staining was performed according to the protocols described by the manufacturer. Antibody titration was performed before the analysis to determine the antibody amount and concentration resulting in the lowest signal for the negative population and the highest signal for the positive population to eliminate nonspecific antibody binding. Unstained cells and isotypes were used as controls. Debris was excluded from gated cells. Data were obtained from $1.10^{4}$ events per analysis.

In addition, randomly selected ADSCs from 5 diabetic donors were cultured until passage 3 for a phenotyping analysis to observe changes in the MSCs phenotype after subculture.

\section{Population Doubling Time Assay}

ADSCs from diabetic (4 donors) and non-diabetic donors ( 5 donors) were cultured in $25 \mathrm{~cm}^{2}$ flasks for 14 days in culture medium at a density a $125.10^{3}$ cells per $25 \mathrm{~cm}^{2}$ flask. Cells were detached from the flask. Viable and dead cells were counted using the Trypan blue staining method. Population doubling time (PDT) and cell viability were determined from passage 2 (P2) to P3 using formula below ${ }^{20}$.

$$
\text { PDT(Days) } \frac{\log 2 \times \Delta \mathrm{t}}{\log (\mathrm{NH})-\log (\mathrm{N} 1)}
$$

$\mathrm{NH}=$ harvested cell number

$\mathrm{NI}=$ seeded cell number

$\Delta \mathrm{t}=$ time from seeding to harvesting (days)

\section{Statistical Analysis}

Numeric data is presented as mean \pm standard deviation. Significant differences between the diabetic group and non-diabetic group were evaluated using independent $t$-tests for normally distributed data and Mann-Whitney U tests for non-normally distributed data. For paired data, significant differences between two group were determined using paired $t$-tests for normally distributed data, Wilcoxon tests for nonnormally distributed data, repeated measure ANOVA for more than two groups with normally distributed data and equal variances. P-values of less than 0.05 were considered statistically significant. Statistical analyses were performed using IBM SPSS Statistic Version 23

\section{RESULTS}

\section{Adipose Tissue from Diabetic Donors Had Fewer SVF}

To evaluate the effect of hyperglycemia on the number and viability of stromal cells in adipose tissues, SVF were isolated from the subcutaneous abdominal adipose tissues of 10 non-diabetic donors and 15 diabetic donors. There was no significant difference in age donors. Blood $\mathrm{HbAlc}$ diabetic donors was significantly higher than non-diabetic donors (Table 1).

Total viable cell counts for SVF from non diabetic donors were significantly higher than those for SVF from diabetic donors $\left(0.97 \pm 0.39 \times 10^{9}\right.$ cells, $0.56 \pm 0.39 \times 10^{9}$ cells, $\mathrm{p}=0.02$, independent $t$-test) (Figure 1A). The diabetic condition did not alter the viability of SVF cells $(98.63 \pm 1.12 \%, 98.20 \pm 1.21 \%$ for non-diabetic and diabetic groups, respectively, $\mathrm{p}=$ 0.38 , independent $t$-test) (Figure 1B). 
Table 1: Donor demographics

\begin{tabular}{llll}
\hline Parameter & Non-diabetic Group & Diabetic Group & P-value \\
\hline Sample size (n) & 10 & 15 & \\
Male & $3(30 \%)$ & $12(80 \%)$ & \\
Female & $7(70 \%)$ & $3(20 \%)$ & \\
Age (year) & $53 \pm 9$ & $54 \pm 8$ & 0.69 \\
HbA1c (\%) & $5.46 \pm 0.40$ & $8.21 \pm 3.17$ & $0.001^{*}$ \\
\hline
\end{tabular}

*statistically significant, Mann-Whitney U test
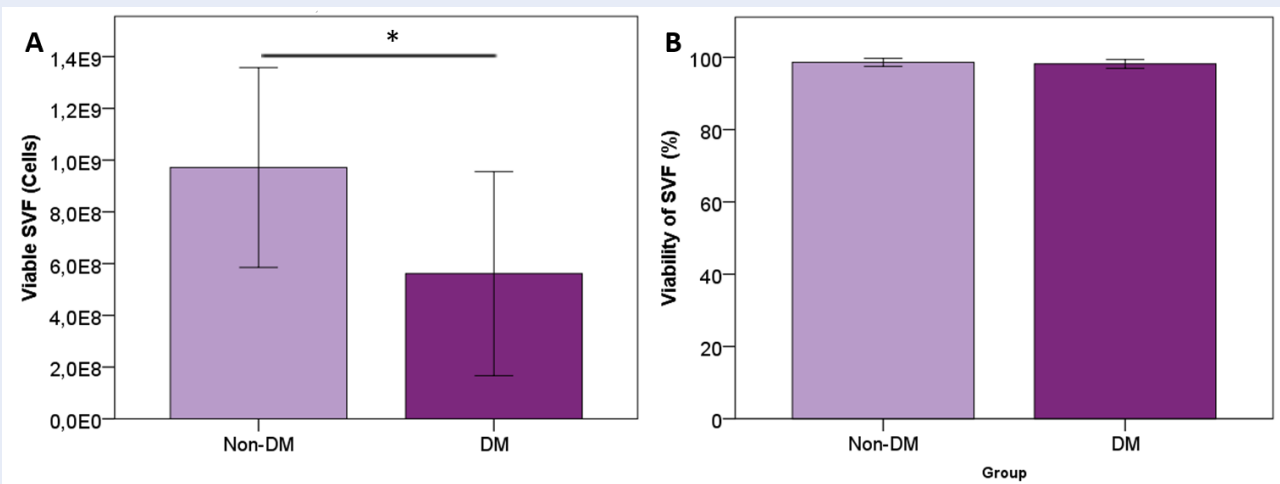

Figure 1: Comparison of viable cell counts and viability for diabetic and non-diabetic SVF. Viable SVF counts are presented per $10 \mathrm{~mL}$ of adipose tissue. Diabetes significantly reduced viable stromal cells in adipose tissue ( ${ }^{*} \mathrm{P}$ $=0.02$ ) but did not change SVF viability $(P>0.05)$. Data are presented as means \pm standard deviation (SD).

\section{Diabetic SVF Formed Fewer Colonies than Non-Diabetic SVF}

Freshly isolated SVF contain MSCs that form fibroblast colonies when seeded at a low density. As expected, fewer fibroblast colonies formed using cultured diabetic SVF than using non-diabetic SVF, for all cell seeding numbers (Table 2).

\section{Three Lineage Differentiation Capacity of MSCs}

Cultured SVF from diabetic and non-diabetic donors were plastic-adherent, had a fibroblast-like morphology, and were able to differentiate into adipocytes, chondrocytes, and osteocytes under specific induction conditions (Figure 2).

\section{Diabetic MSCs with Impaired Phenotypes}

At earlier passage (P1), cells from both groups (nondiabetic and diabetic group) expressed the MSCs markers CD73 (99.44 $\pm 0.34 \%, 97.15 \pm 5.37 \%$, p= 0.21, Mann-Whitney U test) and CD90 (97.30 \pm 2.86\%, $95.06 \pm 6.32 \%, \mathrm{p}=0.90$, Mann-Whitney U test) in similar level. Interestingly, non-diabetic ADSCs had a higher percentage of CD $105^{+}$cells compare to that of diabetic ADSCs $(89.91 \pm 7.14 \%, 57.90 \pm$ $21.36 \%, \mathrm{p}<0.001$, Mann-Whitney U test) (Figure 3). Cells that were positive for hematopoetic lineage markers (CD34/CD45/CD11b/CD19/HLA-DR) were similar from both groups $(4.11 \pm 5.60 \%, 2.07 \pm$ $1.95 \%, p=0.58$, Mann-Whitney U test).

Further cell surface marker analyses were performed using diabetic ADSCs at various passages to investigate if sub-culturing cell can increase the expression of CD73, CD90, and CD105, as well as reduces the expression of CD34/CD45/CD11b/CD105/HLADR. Culturing ADSCs in low-glucose DMEM supplemented with $10 \%$ FBS and $0.05 \mathrm{ng} / \mathrm{mL}$ LAA did not significantly affect CD73 (97.90 $\pm 1.28 \%, 98.23$ $\pm 0.43 \%, 95.70 \pm 2.05, \mathrm{p}=0.32$, for $\mathrm{P} 1, \mathrm{P} 2$, and $\mathrm{P} 3$, respectively, repeated measure ANOVA), CD90 $(96.33 \pm 1.43 \%, 97.13 \pm 1.24 \%, 95.82 \pm 1.02 \%$, $\mathrm{p}=0.63$, repeated measure ANOVA), CD105 expression $(65.14 \pm 5.86 \%, 71.06 \pm 10.27 \%, 64.05 \pm$ $10.04 \%, p=0.70$, repeated measure ANOVA) and CD34/CD45/CD11b/CD19/HLA-DR (1.19 $\pm 0.30 \%$, $0.54 \pm 0.18 \%, 0.23 \pm 0.11 \%, \mathrm{p}=0.07$, repeated measure ANOVA)(Figure 4). 
Table 2: Comparison of diabetic and non-diabetic SVF with respect to fibrobast colony formation

\begin{tabular}{|c|c|c|c|c|}
\hline \multirow[t]{2}{*}{ Group } & \multirow[t]{2}{*}{ Samples } & \multicolumn{3}{|c|}{ Fibroblast colonies per $9 \mathrm{~cm}^{2}$} \\
\hline & & $\mathbf{A}$ & B & C \\
\hline \multirow[t]{6}{*}{ Non-diabetic } & $\mathrm{C} 1$ & 19 & $\mathrm{Na}$ & Uncountable \\
\hline & $\mathrm{C} 2$ & Uncountable & $\mathrm{Na}$ & Uncountable \\
\hline & $\mathrm{C} 3$ & 26 & $\mathrm{Na}$ & Uncountable \\
\hline & $\mathrm{C} 4$ & $\mathrm{Na}$ & Uncountable & Uncountable \\
\hline & $\mathrm{C} 5$ & $\mathrm{Na}$ & 42 & 65 \\
\hline & C6 & $\mathrm{Na}$ & Uncountable & Uncountable \\
\hline \multirow[t]{7}{*}{ Diabetic } & DM1 & 1 & $\mathrm{Na}$ & 5 \\
\hline & DM2 & 1 & $\mathrm{Na}$ & 4 \\
\hline & DM3 & $\mathrm{Na}$ & $\mathrm{Na}$ & 76 \\
\hline & DM4 & $\mathrm{Na}$ & 22 & 30 \\
\hline & DM5 & $\mathrm{Na}$ & 34 & 65 \\
\hline & DM6 & $\mathrm{Na}$ & 11 & $\mathrm{Na}$ \\
\hline & DM7 & 10 & 26 & $\mathrm{Na}$ \\
\hline
\end{tabular}

Na: not available. C: control. DM: diabetes mellitus donors. A, B, and C represent cell seeding densities of $10 \times 10^{3}, 15 \times 10^{3}$, and $20 \times 10^{3}$ cells per well, respectively. Cultured cells that formed unclear separated collonies was reffered to uncountable.
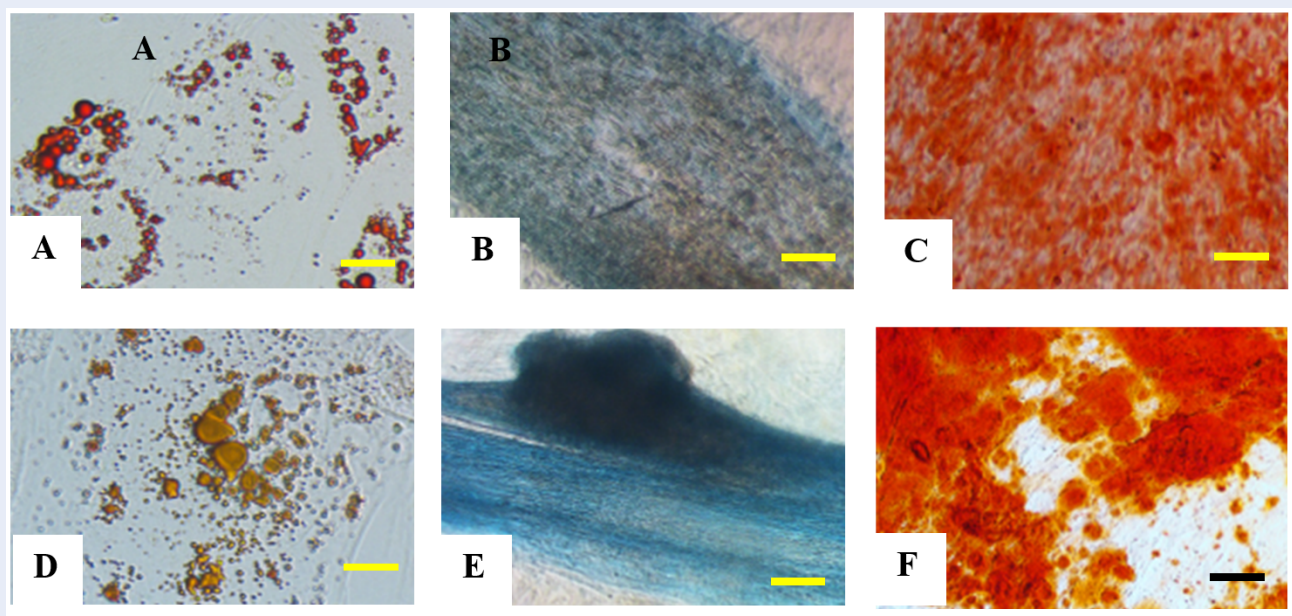

Figure 2: Multilineage differentiation ability of ADSCs from diabetic $(A-C)$ and non-diabetic donors (D-F). Passage 3 cells that reached $80 \%$ confluency were specifically induced to differentiate into adipocytes (A, D), chondrocytes (B, E), and osteocytes (C, F). After 3 days, signs of differentiation were observed. Lipid droplet-containing adipocytes were detected by Oil Red $O$ staining ( $b a r=25 \mu \mathrm{m}$ ), aggrecan-containing chondrocytes were detected by Alcian Blue staining (bar $=250 \mu \mathrm{m})$, and calcium-containing osteocytes were detected by Alizarin Red staining $($ bar $=250 \mu \mathrm{m})$. 


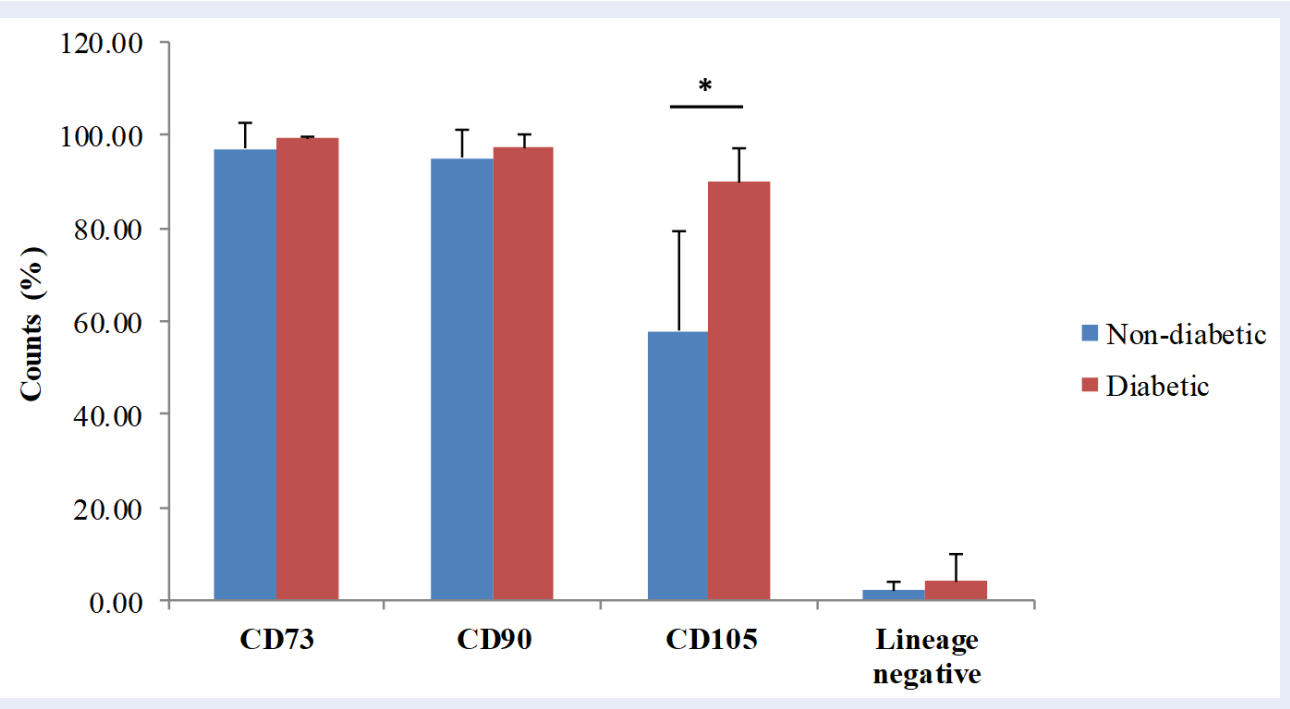

Figure 3: Phenotypes of ADSCs from diabetic and non-diabetic donors. Data represent the percentage of positive cells for each MSCs markers. MSCs expressed CD73, CD90, and CD105 on their surfaces but did not express hematopoetic stem cells (HSCs) markers, such as CD34, CD45, CD11b, CD19, and HLA-DR. Surface marker analyses were performed using passage 1 ADSCs from diabetic donors $(n=12)$ and non-diabetic donors $(n=10)$. Data are presented as mean and standard deviation. ${ }^{*}$ represents significant differences between non-diabetic and diabetic $\operatorname{ADSCs}(p<0.001)$.

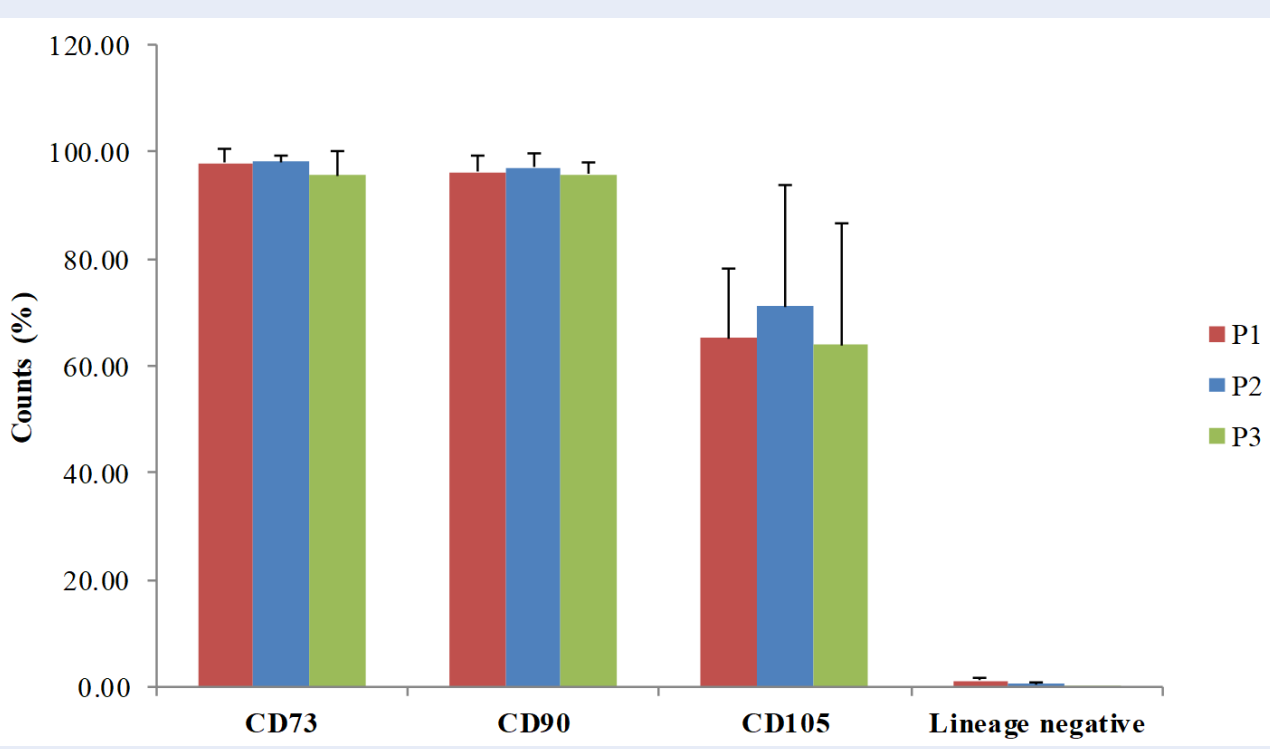

Figure 4: Phenotype of Passage 1 (P1) to P3 ADSCs from diabetic donors. Data are presented as mean \pm SD of the percentage of positive cells for each MSCs marker. Percentages of $\mathrm{CD}_{73}{ }^{+}$and $\mathrm{CD} 90^{+}$cells were maintained at more than $95 \%$, while cell populations expressing hematopoetic markers were less than $2 \%$. CD $105^{+}$cells were less than $95 \%$ of passage $1-3$ cultured diabetic MSCs $(n=5)$. No significant differences between diabetic ADSCs from any passage were observed. 
Diabetic ADSCs Exhibited Slower Proliferation and Lower Viability than Those of NonDiabetic ADSCs

To evaluate whether diabetes affects the proliferation capacity of ADSCs, the PDTs of diabetic and nondiabetic ADSCs were analyzed using the same cell seeding density and culture time (Figure 5). Diabetic ADSCs had a higher PDT value than that of nondiabetic ADSCs in passages 2 (4.43 \pm 2.70 days, 3.04 \pm 0.55 days, $\mathrm{p}=0.27$, independent t-test) and 3 (3.95 \pm 1.55 days, $2.96 \pm 0.91$ days, $\mathrm{p}=0.21$, independent $t$ test) (Figure 6). Diabetic ADSCs required 30\% longer than non-diabetic ADSCs to double their population in passages 2 and 3 . In addition, cell proliferation did not change significantly during subculture in both groups ( $\mathrm{p}=0.78, \mathrm{p}=0.50$ for P2 vs. P3 in non-diabetic and diabetic group, paired $t$-test). Diabetic ADSCs had a lower viability than that of non-diabetic ADSCs in passages $2(77.65 \pm 10.61 \%, 87.13 \pm 10.06 \%$, p= 0.25 , independent $t$-test) and $3(82.70 \pm 8.07 \%, 91.15$ $\pm 3.77 \%, \mathrm{p}=0.04$, independent $t$-test). Passaging improved cell viability slightly in the non-diabetic group ( $\mathrm{p}=0.35$ for P2 vs. P3, paired $t$-test) but not in the diabetic group ( $\mathrm{p}=0.58$ for $\mathrm{P} 2 v s$. $\mathrm{P} 3$, paired $t$-test).

\section{DISCUSSION}

Identifying the effect of diabetes on ADSCs is a necessary starting point for their autologous application for diabetes treatment. In this study, we reported that adipose tissues from the diabetic group have significantly fewer stromal cells number compared to the non-diabetic group. Our results were in line with other studies, that showed fewer MSCs were obtained from diabetic group than from non-diabetic group $^{7,13,21}$. Then, as expected, fewer CFU-Fs were found in the diabetic group than in the non-diabetic group. Stem cells are in the G0 phase, quiscent in in vivo that allow the cells to escape apoptosis and cell senescence, thus they can act as reservoir for tissue replenishment $^{22}$. A trigger, such as pro-inflammatory signal can permit stem cells to re-enter the cell cycle, proliferate and differentiate ${ }^{22}$. Substantial ROS release and pro-inflammatory cytokine, like tumor necrosis factor alpha (TNF $\alpha$ ) production have been found in adipocytes isolated from diabetic mice ${ }^{23,24}$. Other study reported that short term treatment with TNF $\alpha$ enhanced the stemness of stem cells, including the ability of stem cells to form cell colonies, to migrate, and to differentiate ${ }^{25}$. However, overexposure with $\mathrm{TNF} \alpha$ can reduce the proliferative capacity of stem cells ${ }^{26}$. Other study reported that in high glycemic condition, Akt, a signalling pathway that contributes to cell proliferation, is suppressed ${ }^{27}$. Moreover, TNF $\alpha$ can induces apoptosis of stem cells, and apoptosis is enhanced in hyperglycemic culture conditions $^{27-29}$. Thus, a reduce in quiscence may result in the deplete of stem/progenitor cells ${ }^{30}$.

Over-expression of TNF $\alpha$ can also impaired the differentiation ability of stem cells towards osteoblast ${ }^{31}$. Interestingly, we did not find a significant difference between diabetic ADSCs and non-diabetic ADSCs in chondrogenic, osteogenic, and adipogenic diferentiation ability. However, a previous study reported that diabetic ADSCs are more susceptible to adipogenic differentiation, with reduced osteogenic and chondrogenic potencies ${ }^{14}$. This difference between studies might be due to differences in the induction method and the composition of the culture medium.

For clinical applications, ADSCs should meet the minimal standard requirements for MSCs. ADSCs quality was checked based on multipotency and specific cell surface marker expression by flow cytometry $^{32}$. Both of diabetic and non-diabetic MSCs in this study had subset population of hematopoetic markers-expressing cells below than $2 \%$, and subset population of CD73, CD90-expressing cells more than $95 \%$, and were in accordance to the defined criteria by International Society of Cellular Therapy ${ }^{27}$. Interesting finding in this study was the percentage of $\mathrm{CD} 105$-positive $\left(\mathrm{CD}_{105^{+}}\right)$cells in diabetic ADSCs was lower than that in non-diabetic ADSCs and expected value, suggesting a reduced angiogenic potency of cultured diabetic ADSCs. The marker CD105, or endoglin, is an accessory receptor for transforming growth factor beta (TGF- $\beta$ ) and is a biomarker for angiogenesis. However, CD105 expression is not consistently evaluated in all MSCs studies; therefore, data for CD105 expression on diabetic MSCs are limited. Study by Li et al. has showed that mice lacks of CD105 or endoglin expression has impairment in angiogenesis ${ }^{33}$. Moreover, other previous studies in human also showed the impairment of angiogenesis ability in diabetic patients ${ }^{34,35}$. The reduced expression of CD105 based on flow cytometry has also been reported by $\mathrm{Li}$ et al. in vascular endothelial cells via TNF- $\alpha$ in concentration- and timedependent manner ${ }^{36}$.

CD105 is important for cell growth and shows an anti-apoptotic effect ${ }^{37}$. Therefore, the suppression of CD105 may reduce the proliferation and survival of diabetic ADSCs, and this was confirmed in this study. We found that diabetic ADSCs need 30\% longer than non-diabetic ADSCs to double. These data were supported by a previous study showing that $\mathrm{CD} 105^{+} \mathrm{AD}$ SCs exhibit greater proliferation compared to that of 


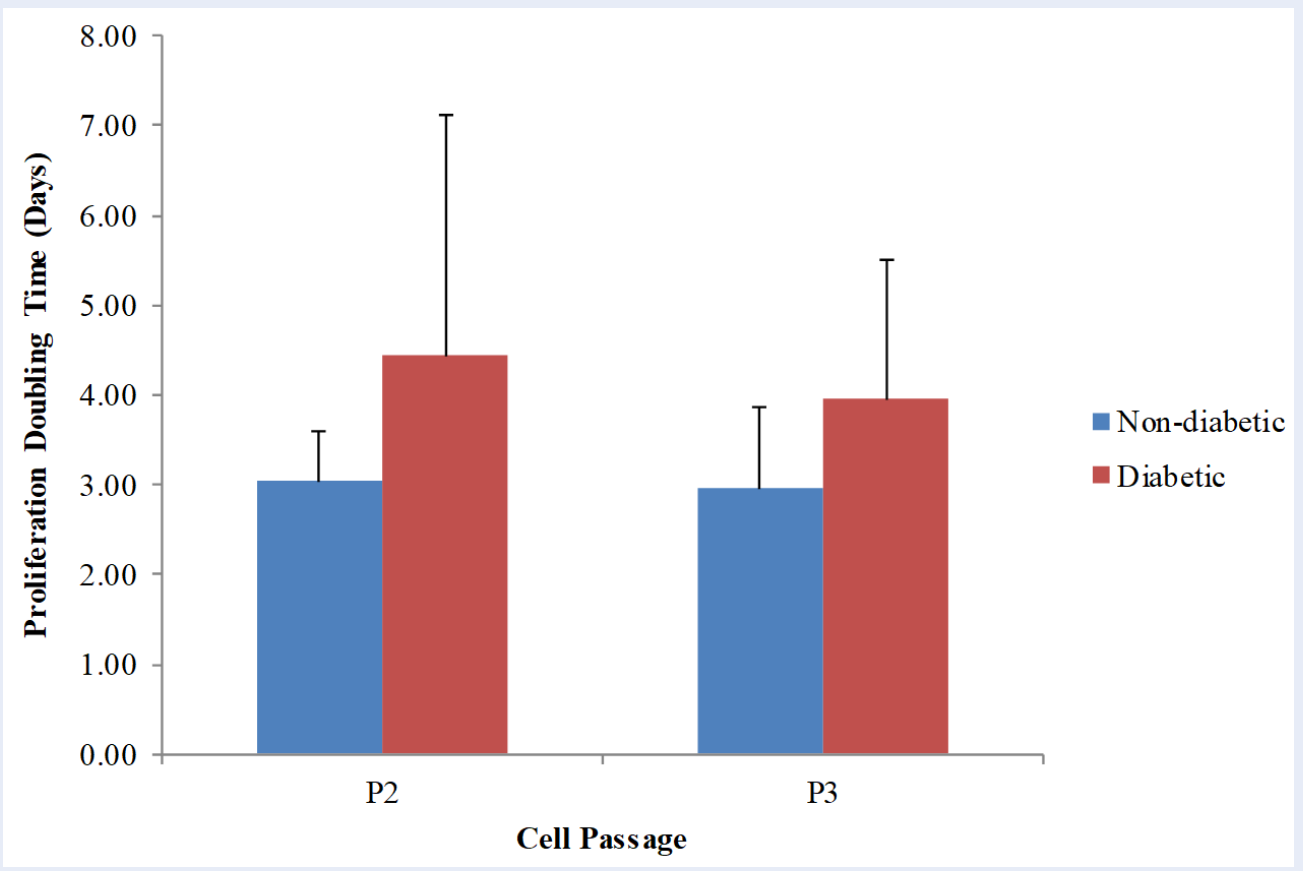

Figure 5: Population doubling time of adipose-derived stem cells from diabetic and non-diabetic donors. Data are presented as average PDTs. Diabetic ADSCs $(n=6)$ proliferated more slowly than non-diabetic ADSCs $(n=6)$ at passage $2-3$, but the difference was not significant. The culture process did not change the proliferation capacity in both groups.

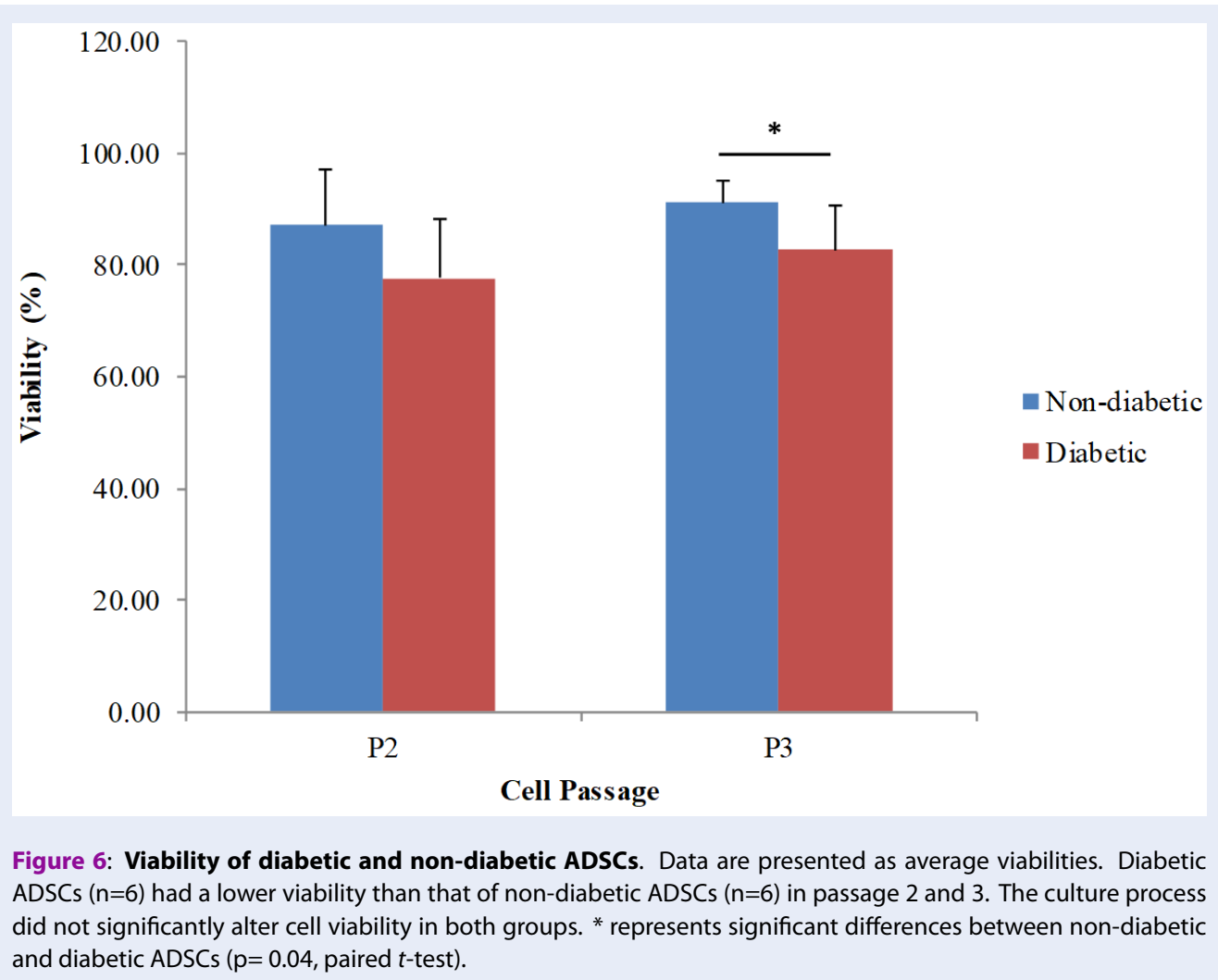


$\mathrm{CD}_{105^{-}} \mathrm{ADSCs}^{37}$. A high glucose concentration (500 mg/dL and $100 \mathrm{mg} / \mathrm{dL}$ ) also leads to senescence, resulting in reduced cell proliferation, compared to low glucose concentration $(100 \mathrm{mg} / \mathrm{dL})^{29}$. The diabetic ADSCs in this study were more prone to cell death upon cell detachment from culture flask that was showed by a slightly lower cell viability compared to non-diabetic ADSCs. It is suggested to be caused bythe loss of anti-apoptotic effect due to the suppression of CD105 in diabetic ADSCs ${ }^{37}$.

$\mathrm{CD}_{105^{+}}$cells are crucial for improving angiogenesis in diabetic patients. Based on other previous study, ${ }^{29}$ we expected that culturing diabetic ADSCs in lowglucose conditions (100 mg/dL glucose) with an antioxidant can increase the percentage of $\mathrm{CD}_{105^{+}}$cells.

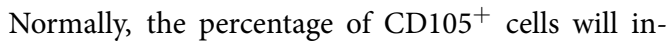
crease after sub-culturing because cultured MSCs are purer than those at earlier passages due to the proliferation of the original CD105 ${ }^{+}$cells ${ }^{38}$. However, in this study, we found that serial passaging failed to increase $\mathrm{CD} 105^{+}$cells in cultured diabetic ADSCs and did not improve cell proliferation and survival. These results indicate that the reduction of cell proliferation and survival due to the suppression of CD105 cannot be reversed by our culturing method. Another study reported that the proliferation and senescence of diabetic MSCs can be improved by insulin treatment ${ }^{29}$. Overall, we concluded that diabetes reduced CD105 expression and ADSCs proliferation, suggesting that the angiogenic potency of diabetic ADSCs is reduced. In order to confirm that, in vitro tube formation assay can be done ${ }^{13}$. Since diabetic ADSCs may have metabolic memory in type 2 diabetes, ${ }^{7}$ we believed that more advanced and controlled culture methods are needed to produce large quantities and to improve the biological functions of diabetic ADSCs, so expected clinical outcomes can be achieved.

In terms of the clinical applications of autologous stem cells for diabetes, the heterogenity of SVF consisting of many types of cells, such as endothelial progenitor cells, pericytes, hematopoetic stem cells, and fibroblasts, known to play role in angiogenesis, may result in a higher potency of SVF than expanded ADSCs. The efficacy of SVF as non-expanded ADSCs for diabetes is suggested to be further elucidated and compared to that of expanded ADSCs.

\section{CONCLUSIONS}

We concluded that diabetes reduced CD105 expression and ADSCs proliferation, suggesting that the angiogenic potency of diabetic ADSCs is reduced. The diabetic ADSCs in this study were also more prone to cell death caused by handling technique compared to non-diabetic ADSCs. Therefore, more advanced culture techniques should be applied to expand ADSCs from diabetic patients to achieve expected clinical outcomes.

\section{ABBREVIATIONS}

ADSCs: adipose-derived stem cells

BMSCs: bone marrow-derived stem cells

CD: cluster of differentiation

CFU-F: colony formation unit-fibroblast

DM: diabetes mellitus

DMEM: Dulbecco's Modified Eagle's Medium

FBS: fetal bovine serum

HbA1c: Hemoglobin A1c

LAA: L-ascorbic acid

MSCs: mesenchymal stem cells

NO: nitric oxide

P: passage

PBS: phosphate-buffered saline

PDT: Population doubling time

ROS: reactive oxygen species

SVF: stromal vascular fractions

TGF- $\beta$ : transforming growth factor beta

TNF $\alpha$ : tumor necrosis factor alpha

\section{COMPETING INTERESTS}

The authors declare that they have no competing interests.

\section{AUTHOR CONTRIBUTION}

Conception and design: KRN, JAP, DSI; contribution in cell culture works: JAP, DSI, MRI, SSH; data collection and entry: SSH, IRA, IRI, IAI, TWI; data analysis and interpretation: KRN, IRA, IRI, JAP, DSI; manuscript writing: KRN, IRA, JAP, DSI; final approval of manuscript: KRN, JAP, DSI.

\section{ACKNOWLEDGEMENTS}

We would also like to thank Editage (www.editage.co $\mathrm{m})$ for English language editing.

\section{REFERENCES}

1. Kolluru GK, Bir SC, Kevil CG. Endothelial dysfunction and diabetes: Effects on angiogenesis,vascular remodeling, and wound healing. Int J Vasc Med 2012;2012:918267.

2. Paneni F, Beckman JA, Creager MA, Cosentino F. Diabetes and vascular disease: Pathophysiology, clinical consequences, and medical therapy: Part. I Eur Heart J. 2013;34:2436-46.

3. Chawla A, Chawla R, Jaggi S. Microvasular and macrovascular complications in diabetes mellitus: Distinct or continuum? Indian J Endocrinol Metab. 2016;20(4):546-51.

4. Mihardja L, Delima, Siswoyo H, Ghani L, Soegando S. Prevalence and determinants of diabetes mellitus and impaired glucose tolerance in Indonesia (A Part of Basic Health Research/Riskesdas). Acta Med Indones-Indones J Intern Med. 2009;41(4):169-74. 
5. Zang L, Hao H, Liu J, Li W, Han W, Mu Y. Mesenchymal stem cell therapy in type 2 diabetes mellitus. Diabetol Metab Syndr. 2017;9(36):1-11.

6. Amin $A H, A b d E Z Y, N a i r ~ D$, et al. Modified multipotent stromal cells with epidermal growth factor restore vasculogenesis and blood flow in ischemic hind-limb of type II diabetic mice. Lab Invest. 2010;90(7):985-96.

7. Shin L, Peterson DA. Impaired therapeutic capacity of autologous stem cells in a model of type 2 diabetes. Stem Cells Transl Med. 2012;1:125-35.

8. Bhansali A, Asokumar P, Walia R, Bhansali S, Gupta V, Jain A et al. Efficacy and safety of autologous bone marrow-derived stem cell transplantation in patients with type 2 diabetes mellitus: A randomized placebo controlled study. Cell Transplant. 2014;23(9):1075-85.

9. Hu J, Li C, Wang L, Zhang X, Zhang M, Gao H, et al. Long term effects of the implantation of autologous bone marrow mononuclear cells for type 2 diabetes mellitus. Endocr J. 2012;59(11):1031-9.

10. Hu J, Wang Y, Gong H, Yu C, Guo C, Wang F, et al. Long term effect and safety of Wharton's jelly-derived mesenchymal stem cells on type 2 diabetes. Exp Ther Med. 2016;12:1857-66.

11. Liu X, Zheng P, Wang X, Dai G, Cheng H, Zhang Z, et al. A preliminary evaluation of efficacy and safety of Wharton's jelly mesenchymal stem cell transplantation in patients with type 2 diabetes mellitus. Stem Cell Res Ther. 2014;5(2):57.

12. Chandravanshi $B$, Bhonde $R$. Shielding engineered islets with mesenchymal stem cells enhance survival under hypoxia. J Cell Biochem. 2017; doi:10.1002/jcb.25885.

13. Dzhoyashvili NA, Efimenko AY, Kochegura TN, Kalinina NI, Koptelova NV, Sukhareva OY, et al. Disturbed angiogenic activity of adipose-derived stromal cells obtained from patients with coronary artery disease and diabetes mellitus type 2. J Transl Med. 2014;12(337):1-13.

14. Cramer C, Freisinger $E$, Jones RK, Slakey DP, Dupin $C L$, Newsome ER, et al. Persistent high glucose concentrations alter the regenerative potential of mesenchymal stem cells. Stem Cells Dev. 2010;19(12):1875-84

15. Sun LY, Li DK, Chen PJ, Ho YYJ, Kuo JS, et al. Expansion of semi-automatic processed human adipose-derived stem cells in medium supplemented with autologous serum and antioxidants. J Stem Cell Res Ther. 2014;4:193.

16. Remelia M, Rosadi I, Rosliana I, Sobariah S, Karina. Optimized method for isolation of regenerative stromal cells from human lipoaspirates. Biomed Res Therapy. 2017;4(5).

17. Markarian CF, Frey GZ, Silveira MD, Chem EM, Milani AR, Ely PB, et al. Isolation of adipose-derived stem cells: A comparison among different methods. Biotechnol Lett. 2014;36:693-702.

18. SundarRaj S, Deshmukh A, Priya N, Krishnan VS, Cherat M, Majumdar AS. Development of a system and method for automated isolation of stromal vascular fraction from adipose tissue lipoaspirate. . Stem Cells Int 2015. 2015;Article ID 109353

19. Caroti MC, Ahn H, Salazar HF, Joseph G, Sanka SB, Willett NJ. A novel technique for accelerated culture of murine mesenchymal stem cells that allows for sustained multipotency. Sci Rep. 2017;7:13334.

20. Suryani D, Pawitan JA, Lilianty J, Purwoko RY, Liem IK, Damayanti L. Comparison of fetal bovine serum and plateletrich plasma on human lipoaspirate-derived mesenchymal stem cell proliferation. Med J Indones. 2013;22:146-51.

21. Cianfarani F, Toietta G, Gi RG, Cesareo E, Zambruno G, Odoris T. Diabetes impairs adipose tissue-derived stem cell function and efficiency in promoting wound healing. Wound Repair Regen. 2013;21:545-53.
22. Nakamura-Ishizu A, Takizawa H, Suda T. The analysis, roles and regulation of quiescence in hematopoieticstem cells. Development. 2014;141:4656-66.

23. Lin $\mathrm{Y}$, Berg $\mathrm{AH}$, lyengar $\mathrm{P}$, Lam TKT, Giacca $\mathrm{A}$, Combs TP et al. The hyperglycemia-induced inflammatory response in adipocytes. J Biol Chem. 2005;280:4617-26.

24. Mirza S, Hossain M, Mathews C, Martinez P, Pino P, Gay JL, et al. Type 2-diabetes is associated with elevated levels of TNFalpha, IL- 6 and adiponectin and low levels of leptin in a population of Mexican American: A cross-sectional study. Cytokine. 2012;57(1):136-42.

25. Ueda M, Fujisawa T, Ono M, Hara ES, Pham HT, Nakajima R, et al. A short-term treatment with tumor necrosisfactor-alpha enhances stem cell phenotype ofhuman dental pulp cells. Stem Cell Res Ther. 2014;5:31.

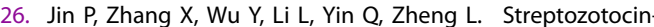
induced diabetic rat-derived bone marrow mesenchyma stem cells have impaired abilities in proliferation, paracrine, antiapoptosis, and myogenic differentiation. Transplant Proc. 2010;4(2):2745-52.

27. Peng C, Ma J, Gao X, Tian P, Li W, Zhang L, et al. High glucose induced oxidative stress and apoptosis in cardiac microvascular endothelial cells are regulated by FoxO3a. PLoS ONE. 2013;8(11):e79739.

28. Ko Kl, Coimbra LS, Tian C, Alblowi J, Kayal RA, Einhorn TA et al. Diabetes reduces mesenchymal stem cells in fracture healing through a TNF $\alpha$-mediated mechanism. Diabetologia. 2015;58(3):633-42.

29. Cramer C, Freisinger E, Jones RK, Slakey DP, Dupin CL, Newsome ER, et al. Persistent high glucose concentrations alter the regenerative potential of mesenchymal stem cells. Stem Cells Dev. 2010;19(12):1875-84.

30. Orford KW, Scadden DT. Deconstructing stem cell selfrenewal: genetic insights into cellcycleregulation. Nature Rev Genet. 2008;9:115-28.

31. Zhao L, Huang J, Zhang H, Wang $Y$, Matesic LE, Takahata $M$, et al. Tumor necrosis factor inhibits mesenchymal stem cell differentiation into osteoblasts via the ubiquitin E3 LigaseWwp1. Stem Cells. 2011;29(10):1601-10.

32. Dominici M, Le KB, Mueller I, Slaper-Cortenbach I, Marin $F$, Krause $D$, et al. Minimal criteria for defining multipotent mesenchymal stromal cells. The International Society. 2006:8:315-7.

33. Li DY, Sorensen LK, Brooke BS, Urness LD, Davis EC, Taylor DG, et al. Defective angiogenesis in mice lacking endoglin. Science. 1999;284:1534-37.

34. Xu F, Zhang C, Graves DT. Abnormal cell repsonses and role of TNF- $\alpha$ in impaired diabetic wound healing;. BioMedRes Int. 2013;2013:Article ID 754802.

35. Fadini GP, Albiero M, deKreutzenberg SV, Boscaro E, Cappellari R, Marescotti $M$. Diabetes impairs stem cell and proangiogenic cellmobilization in humans. Diabetes Care. 2013;36:943-9.

36. Li C, Guo B, Ding S, Rius C, Langa C, Kumar P, et al. TNF $\alpha$ down-regulates $C D 105$ expression in vascular endothelial cells: A comparative study with TGF $\beta 1$. Anticancer Res. 2003;23:1189-96.

37. Fonsatti E, Maio M. CD105+ MSC derived from adipose exhibit greater proliferation compared to CD105- MSC. J Transl Med. 2004;2:18.

38. Cleary MA, Narcisi $R$, Focke $K$, vanderLinden $R$, Brama PAJ, vanOsch GJVM. Expression of CD105 on expanded mesenchy mal stem cells does not predict their chondrogenic potential. Osteoarthr Cart. 2016:24:868-72. 